\title{
$\beta$-Hemoglobinopathies: The Test Bench for Genome Editing-Based Therapeutic Strategies
}

\author{
Gloria Barbarani, Agata Łabedz and Antonella Ellena Ronchi* \\ Dipartimento di Biotecnologie e Bioscienze, Università di Milano-Bicocca, Milan, Italy
}

Hemoglobin is a tetrameric protein composed of two $\alpha$ and two $\beta$ chains, each containing a heme group that reversibly binds oxygen. The composition of hemoglobin changes during development in order to fulfill the need of the growing organism, stably maintaining a balanced production of $\alpha$-like and $\beta$-like chains in a 1:1 ratio. Adult hemoglobin $(\mathrm{HbA})$ is composed of two $\alpha$ and two $\beta$ subunits ( $\alpha 2 \beta 2$ tetramer), whereas fetal hemoglobin ( $\mathrm{HbF})$ is composed of two $\gamma$ and two $\alpha$ subunits ( $\alpha 2 \gamma 2$ tetramer). Qualitative or quantitative defects in $\beta$-globin production cause two of the most common monogenic-inherited disorders: $\beta$-thalassemia and sickle cell disease. The high frequency of these diseases and the relative accessibility of hematopoietic stem cells make them an ideal candidate

OPEN ACCESS

Edited by:

Carsten Werner Lederer,

The Cyprus Institute of Neurology and

Genetics, Cyprus

Reviewed by:

Joseph Borg,

University of Malta, Malta

Anne Galy,

Institut National de la Santé et de la

Recherche Médicale

(INSERM), France

${ }^{*}$ Correspondence:

Antonella Ellena Ronchi

antonella.ronchi@unimib.it

Specialty section:

This article was submitted to Genome Editing in Blood Disorders,

a section of the journal

Frontiers in Genome Editing

Received: 10 June 2020

Accepted: 29 October 2020

Published: 03 December 2020

Citation:

Barbarani G, Łabedz $A$ and Ronchi AE

(2020) $\beta$-Hemoglobinopathies: The

Test Bench for Genome Editing-Based

Therapeutic Strategies.

Front. Genome Ed. 2:571239.

doi: $10.3389 /$ fgeed.2020.571239 for therapeutic interventions based on genome editing. These strategies move in two directions: the correction of the disease-causing mutation and the reactivation of the expression of $\mathrm{HbF}$ in adult cells, in the attempt to recreate the effect of hereditary persistence of fetal hemoglobin $(\mathrm{HPFH})$ natural mutations, which mitigate the severity of $\beta$-hemoglobinopathies. Both lines of research rely on the knowledge gained so far on the regulatory mechanisms controlling the differential expression of globin genes during development.

Keywords: $\beta$-hemoglobinopathies, genome editing, globin genes, hereditary persistence of fetal hemoglobin, programmable endonucleases

\section{INTRODUCTION}

Historically, because of the abundance and accessibility of red blood cells, globins served as a model for major discoveries later extended to other genes. In 1967, hemoglobin was the first human complex protein crystallized (Muirhead et al., 1967); in 1980, the $\beta$-locus was the first cloned gene cluster (Fritsch et al., 1980) and soon became the prototypical model of tissuespecific and developmentally regulated genes. In 1987, the $\beta$-locus control region (LCR) was the first long-distance position-independent enhancer characterized (Grosveld et al., 1987), and the current looping model for the interaction of far apart regulatory regions owes much to the study of globin gene sequential activation during development (Stamatoyannopoulos, 1991; Fraser and Grosveld, 1998). The wealth of data accumulated on globin genes put them now at the frontline of development of genome-editing approaches with therapeutic purposes.

\section{THE GLOBIN GENES}

In man, globin genes are organized in two clusters lying on chromosomes 16 ( $\alpha$ cluster) and 11 ( $\beta$ cluster). A fine-tuned regulation maintains a 1:1 ratio of $\alpha$-like and $\beta$-like chains during 
development to produce first $\mathrm{HBZ}(\zeta 2 \varepsilon 2, \zeta 2 \gamma 2)$, then $\mathrm{HbE}$ $(\alpha 2 \varepsilon 2), \quad \mathrm{HbF}(\alpha 2 \gamma 2)$, and finally $\mathrm{HbA}(\alpha 2 \beta 2)$ together with a small amount of $\mathrm{HbA} 2(\alpha 2 \delta 2)$, in a process called hemoglobin switching.

At the molecular level, the hemoglobin switching involves the establishment of sequential long-range chromatin physical interactions between a common LCR and the different globin promoters active at a given developmental time (with inactive genes being looped out) in a structure called active chromatin hub (ACH) (Carter et al., 2002; Tolhuis et al., 2002; Palstra et al., 2003). The formation of $\mathrm{ACH}$ requires the presence of transcription factors/cofactors that, by binding with the correct affinity to their consensus on DNA, creates the favorable condition for the expression of the gene of interest (Wilber et al., 2011).

\section{$\beta$-HEMOGLOBINOPATHIES}

Qualitative or quantitative defects in the $\beta$-globin production cause the most common monogenic diseases: sickle cell disease (SCD) and $\beta$-thalassemia (Weatherall, 2008; Thein, 2013); both diseases, in particular $\beta$-thalassemias, are very severe in homozygous subjects, whereas symptoms are mild in carriers. In SCD, the amino acid $\beta 6$ Glu $>$ Val substitution leads to the formation of long hydrophobic polymers of $\mathrm{HbS}$ that precipitate within the cell under hypoxic conditions, conferring the typical sickle shape. Sickle cells tend to stick, causing vessel obstruction and, because of their fragility, they frequently undergo hemolysis, finally leading to anemia.

In $\beta$-thalassemias, a wide spectrum of mutations causes the reduction of $\beta$-globin, which can range in severity from total absence $\left(\beta^{0}\right)$ to partial reduction $\left(\beta^{+}\right)$. Causative mutations vary from large deletions to small insertions or deletions (indels) and point mutations within the $\beta$ gene. $\beta$-thalassemia mutations impact on all the different steps of the $\beta$ gene expression regulation (Thein, 2013): transcription (mutations within regulatory regions), RNA processing (splicing mutations), and translation (ATG mutations, non-sense and missense mutations). In rare cases, $\beta$-thalassemia is caused by mutations outside the $\beta$-locus, in genes involved in the basal transcription machinery XPD (Viprakasit et al., 2001) or in the erythroid-specific transcription factor GATA1 (Yu et al., 2002). The common output of $\beta$-thalassemia mutations is a reduced production of functional $\beta$ chains with the consequent precipitation of the excess $\alpha$ chains causing hemolysis and anemia. The presence of dysfunctional erythroid progenitors causes ineffective erythropoiesis (Rivella, 2012) and impacts on hematopoietic stem cells (HSCs) self-renewal (Aprile et al., 2020).

The definitive cure for $\beta$-hemoglobinopathies is HSC transplantation, a treatment available only for the few patients who have an HLA-matched donor. Despite intense efforts, the only drug of some efficacy remains hydroxyurea (Yu et al., 2020), used to treat SCD (Platt, 2008) and, less successfully, $\beta$-thalassemia (Koren et al., 2008; Pourfarzad et al., 2013). Although the condition of $\beta$-diseased patients have greatly improved in the last years (Taher et al., 2009), there is a clear need of new approaches, the most innovative of them being based on genome modifications.

\section{THE LESSON FROM NATURE: HEREDITARY PERSISTENCE OF FETAL HEMOGLOBIN}

The term hereditary persistence of fetal hemoglobin (HPFH) indicates a heterogeneous spectrum of spontaneous mutations, collectively named by their effect, i.e., the maintenance of the expression of fetal $\gamma$-globin in adult stages (Forget, 1998). HPFH alleles, when coinherited with $\beta$-hemoglobinopathies, greatly improve the condition of patients, $30 \%$ of $\mathrm{HbF}$ expression being considered a significant curative threshold able to prevent $\alpha$ free chains polymerization in $\beta$-thalassemias and $\mathrm{HbS}$ precipitation in SCD (Steinberg et al., 2014). Moreover, $\delta \beta$-thalassemias, in which $\delta$ and $\beta$ genes are deleted and $\gamma$-globin is reactivated, in general to a lesser extent than in HPFH, show that even a relatively low level of $\gamma$-globin has beneficial effects on $\beta$-thalassemias (Ottolenghi et al., 1982).

HPFH mutations can be broadly divided in three categories: large deletions affecting the structure of the $\beta$-locus; point mutations within the $\gamma$ promoter that identify "hot-spot" HPFH sequences $(-200,-175,-158$, -distal CCAAT box); and mutations non-linked with the $\beta$-locus (Forget, 1998). Two of these non-linked loci, identified by genome-wide association analysis (GWAS), correspond to BCL11A gene, the most important repressor of $\gamma$-globin (Menzel et al., 2007; Sankaran et al., 2008; Uda et al., 2008) and to its key activator KLF1 (Borg et al., 2010; Zhou et al., 2010). More recently, knock-out studies in HUDEP cells led to the identification of LRF gene (also known as ZBTB7A), which represses $\gamma$-globin independently from BCL11A (Masuda et al., 2016). HPFH mutations within the $\beta$-locus greatly increase the expression of one or both $\gamma$ genes in cis, whereas non-linked HPFH are associated with lower $\gamma$-globin levels (Forget, 1998).

The integration of the genetic data on $\mathrm{HPFH}$ with molecular studies led to the identification of the target sequences amenable for therapeutic genome editing (see below). In 1992, a pioneer study in mice transgenic for the human $\beta$-locus first demonstrated that it is indeed possible to reproduce HPFH (Berry et al., 1992).

\section{THERAPEUTIC GENOME MODIFICATIONS: THE CHOICE OF THE MODIFICATION}

In principle, different therapeutic genomic modifications can be envisaged to cure $\beta$-hemoglobinopathies (Figure 1A):

(1) The addition to the defective cell of an intact $\beta$ gene, that, once delivered and integrated in the genome of the target hematopoietic stem cell, will produce the missing $\beta$ chain under the control of an exogenous regulatory cassette, designed to ensure stable, erythroid-specific, and high-level expression. This approach (not discussed in this review), thanks to intensive efforts in developing safe and efficient vectors and in the improvement of their delivery, reached very significant results 


\section{THERAPEUTIC GENOME EDITING STRATEGIES TO CURE \\ $\beta$-HEMOGLOBINOPATHIES}

A

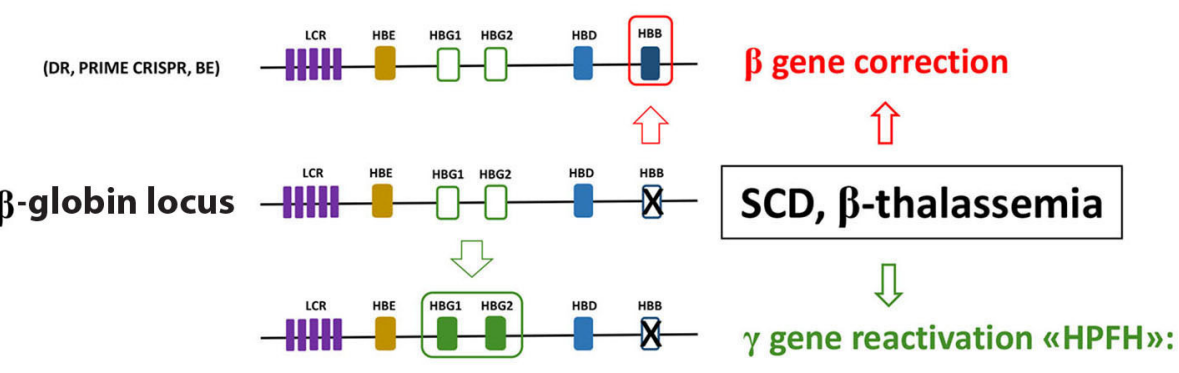

(NHEJ/MMEJ)

- DELETIONS

1) Large deletions within the $\boldsymbol{\beta}$-locus

(see also panel B)

(NHEJ/MMEJ)

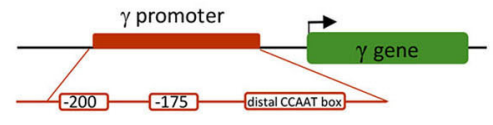

(NHEJ/MMEJ)
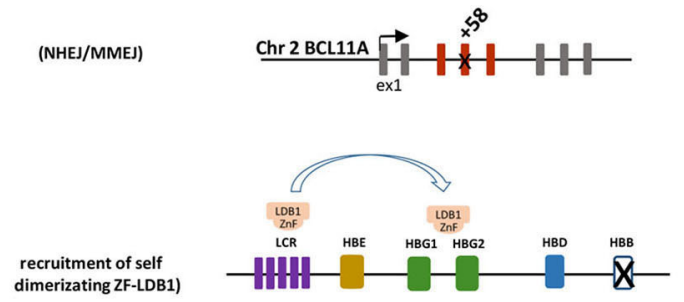

recruitment of self dimerizating ZF-LDB1)

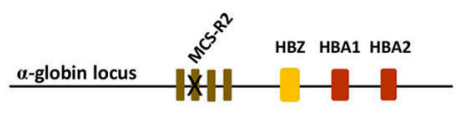

2) Indels within the $\gamma$ promoter to: -abolish binding sites for repressor(s) -introduce binding sites for activator(s)

3) Inactivation of $\gamma$ repressor(s) (e.g. BCL11A +58 erythroid enhancer)

4) Forced looping between the LCR and the $\gamma$ promoter

$\alpha$ downregulation $\rightarrow$ reduced $\alpha: \beta$ unbalance

B

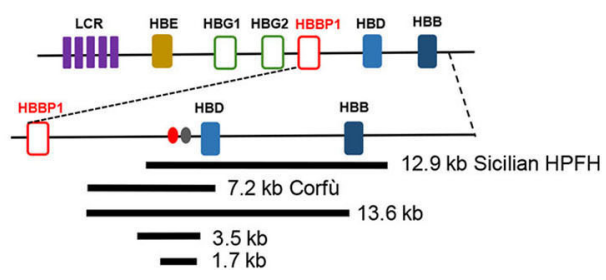

FIGURE 1 | (A) Schematic representation of the different editing strategies developed to cure $\beta$-hemoglobinopathies. These approaches are oriented to correct the mutated $\beta$-globin gene, to reactivate the expression of the fetal $\gamma$ gene in adult cells or to lower $\alpha$-globin expression. The reactivation of $\gamma$ can be obtained via the introduction of different modifications mimicking HPFH caused by large deletions within the $\beta$ locus or by mutations within the $\gamma$ promoter that disrupt the binding site of a repressor or create the binding site of an activator. As an alternative, the disruption of the erythroid-specific enhancer of the $\gamma$ repressor BCL11A abolishes its expression in erythroid cells, thus resulting in $\gamma$ overexpression. A different approach relies on the forced interaction of the LCR with the $\gamma$ promoter obtained by exploiting the self-dimerization property of a fusion ZnF-LDB1 protein recruited on these regions. The detrimental effect of the $\alpha$ : $\beta$ chain imbalance can be mitigated by mutating the MCS-R2 $\alpha$-globin enhancer, in order to reduce $\alpha$ expression. These different strategies exploit different enzymes/cellular pathway described in the text: HDR, homology-directed repair; BE, base editing; NHEJ, non-homologous end joining; MMEJ, microhomology end joining. (B) Schematic representation of the deletions within the $\beta$-locus discussed in the text. Ovals represent the BCL11A (red) and the polypyrimidine (gray) sites thought to be responsible for $\gamma$ repression. 
(Ikawa et al., 2019; Magrin et al., 2019). Importantly, the optimization of protocols developed by gene addition approaches represents a knowledge asset fundamental for bringing genome editing approaches to clinical application.

(2) The exact correction of the mutation causing the disease (gene editing), with the advantage of having the $\beta$ gene expressed under the endogenous regulatory sequences, thus ensuring a perfectly regulated and stable expression with no risk of insertional mutagenesis. This procedure is particularly attractive for point mutations such as the $\beta 6 \mathrm{Glu}>$ Val SCDcausing mutation or for some $\beta$-thalassemia mutations, with the caveat that their extreme heterogeneity would require the design of patient-specific editing strategies. Under this aspect, this approach is worth only for mutations with high frequencies in given populations, as for the $H B B-28 \mathrm{~A}>\mathrm{G} \beta$-thal mutation in Southeast Asia or for the $\beta^{0} 39 \mathrm{C}>\mathrm{T}$ and $\beta^{+}$thal IVS-I-110G $>\mathrm{A}$ mutations in the Mediterranean area (https://www.ithanet.eu/) (Kountouris et al., 2014).

In an extended perspective, the substitution of the mutated $\beta$ gene with a wild-type $\beta$ gene by homologous recombination could combine gene addition and gene editing to create a "universal" substitution cassette, which would minimize the risk of insertional mutagenesis (Cai et al., 2018).

(3) The introduction within the genome of modifications mimicking $\mathrm{HPFH}$, in order to reactivate the expression of the fetal $\gamma$-globin gene and to compensate for the missing/defective $\beta$-globin expression.

(4) The reduction of the expression of $\alpha$-globin, an important $\beta$-thalassemia modifier, as demonstrated by the milder clinical outcome of patients coinheriting $\alpha$ - and $\beta$-thalassemia (Thein, 2008; Mettananda et al., 2015). Reduced $\alpha$ levels indeed reduce the $\alpha: \beta$ chain imbalance, which represent a major problem in $\beta$-hemoglobinopathies. This effect has been achieved experimentally by deleting the MCS-R $\alpha$ enhancer (Mettananda et al., 2017).

\section{THE ADVENT OF PROGRAMMABLE ENDONUCLEASES IN THE EDITING OF GLOBIN GENES: THE SEARCH FOR THE BEST COMPROMISE BETWEEN PRECISION AND EFFICIENCY}

In 1985, Oliver Smithies first exploited homologous recombination (HR) to introduce an exogenous DNA sequence within the $\beta$-locus (Smithies et al., 1985), demonstrating the feasibility of this approach. Since then, HR was used to generate gene knock-out models (including the KO of GATA1 (Pevny et al., 1991) and KLF1 (Nuez et al., 1995; Perkins et al., 1995)), by inserting exogenous DNA in the desired target. However, the very low efficiency of gene targeting, the consequent need of selecting the modified cells, and the technical difficulties of the method discouraged clinical applications (Vega, 1991).

The scenario radically changed with the advent of programmable endonucleases: zinc finger ( $\mathrm{ZnF})$ and TALENs first and now, CRISPR/Cas9 and its derivatives (Cornu et al.,
2017; Komor et al., 2017). These nucleases introduce doublestrand breaks (DSBs) with extreme specificity at the target genomic position. CRISPR/Cas9 is the most flexible system: its cutting specificity relies on a short guide RNA (sgRNA) and only requires the additional presence of an adjacent genomic protospacer adjacent motif (PAM) for its cut [this limit is actually being solved by the "near-PAM-less"-engineered CRISPR-Cas9 variants (Walton et al., 2020)]. In order to minimize possible off targets, different solutions are under study: better algorithms for the prediction of optimal DNA targets, optimized sgRNAs, engineered proto-spacers and Cas enzymes improved on the basis of thermodynamical models (Chen, 2019).

Once generated, DSBs are resolved by different DNA repair cellular pathways:

(i) The homology-directed repair (HDR) high-fidelity system that uses a donor template (the sister identical chromatid in physiological conditions) to repair DSBs when cells are in S and G2 phases. The implication is that HDR is poorly efficient in non-dividing HSC (Dever and Porteus, 2017), the target cell for therapeutic correction of $\beta$-hemoglobinopathies.

(ii) The non-homologous end joining (NHEJ) error-prone system acting in all cell cycle phases that inserts small indels at the site of the lesion, resulting in the disruption of the target sequence.

(iii) The microhomology end-joining (MMEJ) (Wang and $\mathrm{Xu}, 2017)$ error-prone system, which exploits small homology domains to align the broken filaments and close the gap. This molecular mechanism introduces deletions encompassing the microhomology regions flanking the break sites.

On these premises, the design of HDR recombination-based therapeutic strategies is difficult because of the requirement for a codelivered donor DNA template, of the low efficiency of HDR in HSCs and of the competition of the unwanted NHEJ and MMEJ error-prone repair systems. Despite these problems, the correction of the SCD mutation in HSCs was obtained by using both ZnF (Hoban et al., 2015) and CRISPR nucleases (Dever et al., 2016). However, the efficiency of the correction, assessed in HSCs in vitro, dramatically decreased after transplantation in vivo, confirming that HSCs are more resistant to HDR-based editing than more mature progenitors (Hoban et al., 2015) and that a selection step could be required to enrich for HSC-edited cells, capable of long-term correction in vivo (Dever et al., 2016). Instead, NHEJ is more flexible and allow to reach an efficiency up to $\approx 90 \%$ of edited HSCs that is maintained in vivo (Genovese et al., 2014; Chang et al., 2017; Charlesworth et al., 2018; Psatha et al., 2018; Wu et al., 2019).

The "perfect" editing should leave no trace, to avoid unintended off-target mutations and should at the same time guarantee high editing efficiency with reduced toxicity for HSCs. To reach this goal, an intense optimization work has been focused on the different steps of the genome editing procedure: the development of new editing reagents [single-strand DNA donor templates (Park et al., 2019), modified sgRNA (De Ravin et al., 2017; Park et al., 2019), pre-complexed ribonucleoproteins (RNPs) (Gundry et al., 2016)] and their integration in improved platforms for their delivery (Lino et al., 2018; Lattanzi et al., 2019; Schiroli et al., 2019). This massive effort finally led to 
the generation of selection-free HSCs of therapeutic potential (Genovese et al., 2014; DeWitt et al., 2016; Porteus, 2016; Yu et al., 2016; Wu et al., 2019).

\section{THE EDITING OF GLOBIN GENES INSPIRED BY HPFH}

NHEJ has been used to generate two classes of HPFH-inspired mutation: large deletions within the $\beta$-locus, to remove putative $\gamma$-globin repressive regions, and small indels within the $\gamma$-globin promoter or within the regulatory regions driving the erythroid expression of the $\gamma$-globin repressor BCL11A (Bauer et al., 2013; Canver et al., 2015). Large deletions focus around the critical "HPFH $\gamma \delta$-region" 5 ' to the $\delta$ gene, deleted with different breakpoints in several HPFH [https://www.omim.org/entry/ 141749; https://www.ithanet.eu/; (Kountouris et al., 2014)]. This region is generally lost in deletions involving $\delta$ and $\beta$ genes and causing HPFH, whereas it is retained in $\delta \beta$-thalassemia deletions, which similarly remove $\delta$ and $\beta$ genes but with little increase of $\gamma$-globin expression. This observation led to hypothesize that this region contains an element capable to repress the $\gamma$ genes in cis. The CRISPR-mediated deletion corresponding to the 12.9-kb Sicilian HPFH, spanning from $3.2 \mathrm{~kb}$ upstream of the $\delta$ gene to the $3^{\prime}$ flanking region of the $\beta$ gene, gave indeed a $\mathrm{HPFH}$ phenotype (increase in $\gamma$-globin with concomitant drop of $\beta$-globin expression) in HUDEP cells and in human ex vivo HSC-derived erythroblasts (Ye et al., 2016). The same result ( $\gamma$-globin increased and $\beta$-globin decreased) was obtained by the CRISPR-mediated deletion (or inversion) of a large 13.6$\mathrm{kb}$ region starting downstream to the pseudo- $\beta 1$ (HBBP1) gene and extending into the $\beta$ gene (Antoniani et al., 2018). The $5^{\prime}$ border of this deletion corresponds to the $5^{\prime}$ breakpoint of the Corfù $\delta \beta$-thal 7.2-kb deletion (Wainscoat et al., 1985) that ends in the $\delta$ gene and is not associated with HPFH in vivo in humans (except in some rare cases, in homozygotes, in which an additional independent mutation in the downstream $\beta$ gene is present (Kulozik et al., 1988). The CRISPR-mediated deletion of the 7.2-kb Corfù region and of two smaller internal regions of 3.5 and $1.7 \mathrm{~kb}$, centered around a BCL11A binding site and a polypyrimidine stretch (Figure 1B), thought to mediate $\gamma$ globin repression (Sankaran et al., 2011), resulted in a very little $\gamma$-globin increase (Antoniani et al., 2018; Chung et al., 2019). These results indicate that the $1.7-\mathrm{kb}$ element and its surrounding sequences per se are not an autonomous $\gamma$-globin silencer, as also suggested by previous studies (Galanello et al., 1990; Calzolari et al., 1999; Gaensler et al., 2003; Chakalova et al., 2005). Instead, they suggest a more complex scenario, where the competition with $\beta$-globin expression, the perfect distance/order between intergenic enhancer/repressor, and the enhancers delimitating the locus (the LCR and the 3 'DNAseI hypersensitive site), all together concur to the correct $\gamma / \beta$ gene expression (and to $\gamma$-globin increase, when perturbed in $\mathrm{HPFH})$.

The effects of distorting the architecture of the $\beta$-locus can be turned in an advantage: Dr. Blobel and colleagues obtained a great increase in $\gamma$-globin (with $\beta$-globin reduction) by tethering
LDB1 to the LCR and to the $\gamma$-globin promoter, thus forcing their looping (Deng et al., 2014). This result again highlights the importance of the competition between $\gamma$ and $\beta$ genes for the LCR.

HPFH mutation mapping within the $\gamma$-globin promoter alters the binding of transcription factors/cofactors. Theoretically, the $\gamma$-globin upregulation can be obtained either by increasing the binding of an activator or by decreasing the binding of a repressor. Both cases are observed in HPFH. Mutations at positions $-198,-175$, and -113 create new binding sites for erythroid transcriptional activators [KLF1 (Wienert et al., 2017), TAL1 (Wienert et al., 2015), GATA1 (Martyn et al., 2019), respectively]. Other mutations clustered around position -200 and around the distal CCAAT box $(-115)$ reduce the binding of the $\gamma$-globin repressors LRF and BCL11A, respectively (Liu et al., 2018; Martyn et al., 2018).

Consistently, the CRISPR-mediated disruption of these two binding sites resulted in a relevant increase in $\gamma$-globin expression (Traxler et al., 2016; Weber et al., 2020). Of note, the editing of the -158 ("XmnI-G $\gamma$-site"), known to be influenced by a QTL on chromosome 8 (Garner et al., 2002), only marginally increased $\gamma$-globin expression (Weber et al., 2020), suggesting that possible background effects might be taken into account when considering editing for therapeutic purposes.

The existence of two highly homologous $\gamma$-globin genes poses specific editing issues: the double-stranded DNA cut at the gRNA recognition sites in the HBG2 and HBG1 promoters could result in NHEJ-mediated joining of the two ends with loss of the intergenic $(\approx 5 \mathrm{~kb})$ genomic sequence in variable proportion (Traxler et al., 2016; Antoniani et al., 2018). Thus, the editing of these $\gamma$-globin regions can result either in the mutation of a single or both HBG genes or in the deletion of the intergenic region, with different resulting percentages of $\gamma$-globin induction. Moreover, given the presence of short repeats within the promoter, MMEJ can also occur (Traxler et al., 2016; Weber et al., 2020).

NHEJ can also be used to destroy the specific erythroid expression of repressors, such as BCL11A or, in principle, of LRF (both proteins have important roles in other hematopoietic cell types that must be preserved). On this front, four clinical trials based on targeting a GATA1-binding site within the intronic +58 (Canver et al., 2015) erythroid-specific BCL11A enhancer are ongoing (Hirakawa et al., 2020).

Theoretically, all the different genes involved in the $\gamma$-globin repression identified so far, including BCL11A, LRF, SOX6, and DRED are possible targets for genome editing, with the general caveat that their ablation should not perturb stem cell viability, their engraftment and differentiation potential. For example, the ubiquitous knockdown of BCL11A impairs normal HSC function and lymphopoiesis (Luc et al., 2016); LRF (Maeda et al., 2009), SOX6 (Cantu et al., 2011), and KLF1 (Nuez et al., 1995; Perkins et al., 1995) are instead required for proper erythroid differentiation. In this latter case, the need of fine-tuning the downregulation of the $\gamma$-globin repressor in order to lead to an appreciable $\gamma$-globin increase while maintaining a correct erythroid differentiation could represent an insurmountable obstacle. 
Overall, the success obtained in reactivating $\gamma$-globin expression at therapeutic levels demonstrates that this strategy can work. Theoretically, the possibility to generate multiple HPFH mutations could further increase $\gamma$-globin expression.

Importantly, beside the final goal of its clinical application, the relative ease-of-use of the CRISPR-based editing techniques represents a formidable tool to answer the unsolved questions on the molecular mechanisms regulating the hemoglobin switching.

\section{BEYOND CRISPR/CAS9: PRIME-CAS AND BE-CAS}

The use of HDR to correct $\beta$-disease mutations is limited by its low efficiency and by the downstream activation of p53, which can induce toxicity and, even worse, the possible selection of potentially harmful $\mathrm{p} 53^{\text {low }}$ cells (Haapaniemi et al., 2018; Ihry et al., 2018). To overcome this problem, a new generation of engineered Cas9 that do not introduce DBSs (also avoiding unwanted NHEJ/MMEJ events triggered by the DBSs) and do not require donor DNA are under development. They rely on catalytically inactive Cas9 fused to a modified reverse transcriptase (prime editing) or to basespecific DNA deaminase enzymes [base editors (BEs)]. As for many innovations, these newcomers in the CRISPR toolbox have been tested on $\beta$-disease mutations. Prime editing has been used to correct the $\beta 6 \mathrm{Glu}>\mathrm{Val}$ SCD mutation artificially introduced in HEK-293T cells (Anzalone et al., 2019). Dr. Bauer and colleagues recently demonstrated the versatility of $\mathrm{BE}$ by disrupting the GATA1-binding site within the +58 BCL11A erythroid-specific enhancer. The obtained HSC-edited cells express $\mathrm{HbF}$ at levels similar to those obtained by the NHEJ-mediated disruption of the same site and are capable of multi-lineage repopulation in serial transplantation experiments (Zeng et al., 2020). In addition, the simultaneous multiplex edit of the $\beta$-thal $-28 \mathrm{~A}>\mathrm{G}$ mutation in the TATA box of the $\beta$ promoter increased $\beta$-globin production in the same cells.

Instead, Beam Therapeutics recently presented data relative to two therapeutic approaches based on $\mathrm{BE}$, the first recreating an HPFH mutation and the second converting HbS into HbGMakassar, a naturally occurring human variant that does not cause sickling ${ }^{1}$.

Although at present the issues of unwanted bystander/off target mutations remain to be explored, it is clear that Prime editing and $\mathrm{BE}$ represent important new instruments for genome

${ }^{1}$ https://investors.beamtx.com/news-releases/news-release-details/beamtherapeutics-reports-additional-data-asgct-annual-meeting
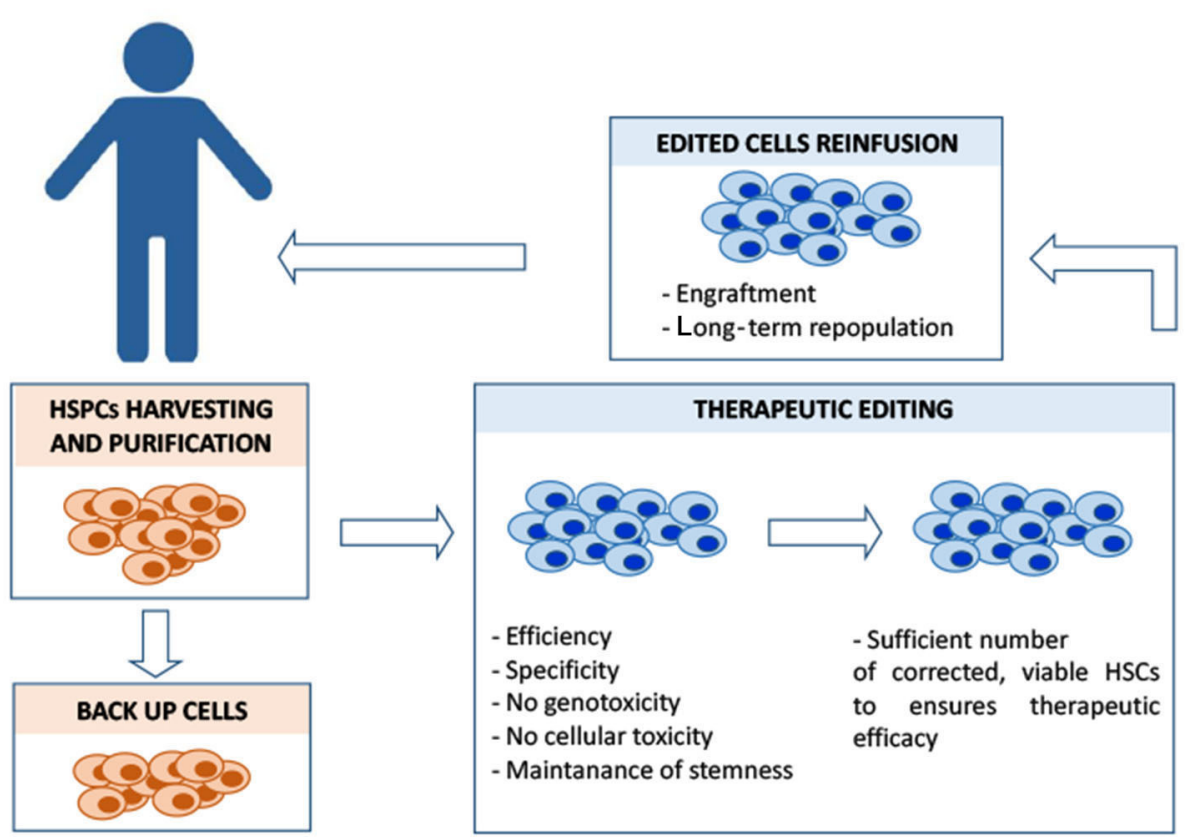

FIGURE 2 | Overview of the different steps of HSC autologous transplantation and of its major critical issues. In the case of $\beta$-hemoglobinopathies, ineffective erythropoiesis and a compromised bone marrow microenvironment sensibly reduce the yield of CD34+HSCs amenable for the editing process, posing a serious problem in a clinical-scale setting. Different mobilization protocols are currently used to maximize the yield of harvested hematopoietic stem progenitor cells (HSPCs) that must also include backup cells to be reinfused into the patient in case of engraftment failure. Editing should ensure efficiency (in terms of complete allelic correction and percentage of edited cells) and, at the same time, minimize the exposure to editing reagents, to reduce the risk of unwanted mutations. Editing manipulations must preserve the population of $\mathrm{CD}_{3} 4^{+}$long-term repopulating cells. Before the reinfusion of the edited cells, the patient is treated with myeloablative agents to maximize the engraftment of the edited cells within the bone marrow niche. The conditioning regimen should be designed to guarantee the optimal risk-benefit balance between toxicity and efficacy of the engraftment, in order to achieve a stable, long-term therapeutic bone marrow repopulation. 
editing, with the perspective to become even more attractive with the ongoing development of $\mathrm{BE}$ enabling more transition substitutions (Komor et al., 2018).

\section{CONCLUDING REMARKS}

The number of genome-editing tools is rapidly increasing (Papasavva et al., 2019; Doudna, 2020), holding the promise to reach in the near future a safe, precise, and efficient editing of $\beta$-disease mutations, via different strategies. The availability of different molecular options (HDR, NHEJ, and BE based, Figure 1) poses the problem of the evaluation of the pros and cons of each strategy (Ikawa et al., 2019; Papasavva et al., 2019): HDR-based approaches could ensure a higher precision at the expenses of HSC correction efficiency, whereas NHEJ is more efficient but less precise. Base editing, which does not require double-strand breaks, could be a safer option when a nucleotide substitution is required. Beside the choice of the optimal genetic modification, other issues remain open, first of all those related to unforeseeable genotoxicity (with the serious concern of inducing hyperproliferative/leukemic mutations in HSCs), the efficiency of the correction and the optimization of the delivery of genome editing reagents to target cells in conditions that preserve their stemness. Moreover, the clinical translation of these approaches requires the definition of scalable protocols to obtain under non-invasive conditions, a sufficient number of autologous HSCs amenable for the editing procedures and capable of optimal engraftment (in addition to backup cells to be reinfused in the patient in the case of engraftment failure) (Figure 2). This last point involves the identification of the best preparative conditioning regimen of the patient to allow efficient engraft of the corrected HSCs within the recipient niche (Psatha et al., 2016). Despite these difficulties, the recent announcement of the curative response of the first three patients (carrying a transfusion-dependent

\section{REFERENCES}

Antoniani, C., Meneghini, V., Lattanzi, A., Felix, T., Romano, O., Magrin, E., et al. (2018). Induction of fetal hemoglobin synthesis by CRISPR/Cas9mediated editing of the human beta-globin locus. Blood 131, 1960-1973. doi: 10.1182/blood-2017-10-811505

Anzalone, A. V., Randolph, P. B., Davis, J. R., Sousa, A. A., Koblan, L. W., Levy, J. M., et al. (2019). Search-and-replace genome editing without double-strand breaks or donor DN. A. Nature 576, 149-157. doi: 10.1038/s41586-019-1711-4

Aprile, A., Gulino, A., Storto, M., Villa, I., Beretta, S., Merelli, I., et al. (2020). Hematopoietic stem cell function in beta-thalassemia is impaired and is rescued by targeting the bone marrow niche. Blood 136-610-22. doi: 10.1182/blood.2019002721

Bauer, D. E., Kamran, S. C., Lessard, S., Xu, J., Fujiwara, Y., Lin, C., et al. (2013).An erythroid enhancer of BCL11A subject to genetic variation determines fetal hemoglobin level. Science 342, 253-257. doi: 10.1126/science. 1242088

Berry, M., Grosveld, F., and Dillon, N. (1992). A single point mutation is the cause of the Greek form of hereditary persistence of fetal haemoglobin. Nature 358, 499-502. doi: 10.1038/358499a0

Borg, J., Papadopoulos, P., Georgitsi, M., Gutierrez, L., Grech, G., Fanis, P., et al. (2010). Haploinsufficiency for the erythroid transcription factor KLF1 $\beta$-thalassemia and the SCD mutation) with CRISPR-Cas9edited cells targeting BCL11A (CRISPR Therapeutics and Vertex CTX001 clinical trial ${ }^{2 \& 3}$ ), clearly highlights the clinical potential of gene therapy. The advent of this new era urges the need to make these approaches affordable and available in low-resource settings/countries, where a large number of patients is waiting for a cure.

\section{AUTHOR CONTRIBUTIONS}

AR conceived and wrote the manuscript. GB contributed with ideas and discussion. GB and AŁ contributed in the organization of the manuscript. All authors contributed to the article and approved the submitted version.

\section{FUNDING}

This project has received funding from the European Union's Horizon 2020 research and innovation program under the Marie Skłodowska-Curie grant agreement No. 813091 [age-related changes in hematopoiesis (ARCH)].

\section{ACKNOWLEDGMENTS}

We are indebted with Dr. Sergio Ottolenghi for the generous sharing of his deep knowledge of the $\beta$-locus and of its mutations and with Christina Pitsillidou and Sarah Stucchi for their suggestions in preparing figures.

\begin{abstract}
${ }^{2}$ https://www.globenewswire.com/news-release/2020/06/12/2047260/ 0/en/CRISPR-Therapeutics-and-Vertex-Announce-New-ClinicalData-for-Investigational-Gene-Editing-Therapy-CTX001-in-SevereHemoglobinopathies-at- the-25th-Annual-European-Hematology-Associ. html (accessed October 5, 2020).
\end{abstract}

${ }_{3}^{3}$ http://ir.crisprtx.com/news-releases/news-release-details/crispr-therapeuticsand-vertex-pharmaceuticals-announce-priority (accessed October 5, 2020). causes hereditary persistence of fetal hemoglobin. Nat. Genet. 42, 801-805. doi: 10.1038/ng.630

Cai, L., Bai, H., Mahairaki, V., Gao, Y., He, C., Wen, Y., et al. (2018). A universal approach to correct various HBB gene mutations in human stem cells for gene therapy of beta-thalassemia and sickle cell disease. Stem Cells Transl. Med. 7, 87-97. doi: 10.1002/sctm.17-0066

Calzolari, R., McMorrow, T., Yannoutsos, N., Langeveld, A., and Grosveld, F. (1999). Deletion of a region that is a candidate for the difference between the deletion forms of hereditary persistence of fetal hemoglobin and deltabetathalassemia affects beta- but not gamma-globin gene expression. EMBO J. 18, 949-958. doi: 10.1093/emboj/18.4.949

Cantu, C., Ierardi, R., Alborelli, I., Fugazza, C., Cassinelli, L., Piconese, S., et al. (2011). Sox6 enhances erythroid differentiation in human erythroid progenitors. Blood 117, 3669-3679. doi: 10.1182/blood-2010-04-282350

Canver, M. C., Smith, E. C., Sher, F., Pinello, L., Sanjana, N. E., Shalem, O., et al. (2015). BCL11A enhancer dissection by Cas9-mediated in situ saturating mutagenesis. Nature 527, 192-197. doi: 10.1038/ nature15521

Carter, D., Chakalova, L., Osborne, C. S., Dai, Y. F., and Fraser, P. (2002). Longrange chromatin regulatory interactions in vivo. Nat. Genet. 32, 623-626. doi: $10.1038 / \mathrm{ng} 1051$ 
Chakalova, L., Osborne, C. S., Dai, Y. F., Goyenechea, B., Metaxotou-Mavromati, A., Kattamis, A., et al. (2005). The Corfu deltabeta thalassemia deletion disrupts gamma-globin gene silencing and reveals post-transcriptional regulation of HbF expression. Blood 105, 2154-2160. doi: 10.1182/blood-2003-11-4069

Chang, K. H., Smith, S. E., Sullivan, T., Chen, K., Zhou, Q., West, J. A., et al. (2017). Long-term engraftment and fetal globin induction upon BCL11A gene editing in bone-marrow-derived CD34 $(+)$ hematopoietic stem and progenitor cells. Mol Ther Methods Clin Dev. 4, 137-148. doi: 10.1016/j.omtm. 2016.12.009

Charlesworth, C. T., Camarena, J., Cromer, M. K., Vaidyanathan, S., Bak, R. O., Carte, J. M., et al. (2018). Priming human repopulating hematopoietic stem and progenitor cells for Cas9/sgRNA gene targeting. Mol. Ther. Nucleic Acids 12, 89-104. doi: 10.1016/j.omtn.2018.04.017

Chen, S. J. (2019). Minimizing off-target effects in CRISPR-Cas9 genome editing. Cell Biol. Toxicol. 35, 399-401. doi: 10.1007/s10565-019-09486-4

Chung, J. E., Magis, W., Vu, J., Heo, S. J., Wartiovaara, K., Walters, M. C., et al. (2019). CRISPR-Cas9 interrogation of a putative fetal globin repressor in human erythroid cells. PLoS ONE 14:e0208237. doi: 10.1371/ journal.pone.0208237

Cornu, T. I., Mussolino, C., and Cathomen, T. (2017). Refining strategies to translate genome editing to the clinic. Nat. Med. 23, 415-423. doi: 10.1038/ nm.4313

De Ravin, S. S., Li, L., Wu, X., Choi, U., Allen, C., Koontz, S., et al. (2017). CRISPR-Cas9 gene repair of hematopoietic stem cells from patients with Xlinked chronic granulomatous disease. Sci Transl Med. 9, 1-10. doi: 10.1126/ scitranslmed.aah3480

Deng, W., Rupon, J. W., Krivega, I., Breda, L., Motta, I., Jahn, K. S., et al. (2014). Reactivation of developmentally silenced globin genes by forced chromatin looping. Cell 158, 849-860. doi: 10.1016/j.cell.2014.05.050

Dever, D. P., Bak, R. O., Reinisch, A., Camarena, J., Washington, G., Nicolas, C. E., et al. (2016). CRISPR/Cas9 beta-globin gene targeting in human haematopoietic stem cells. Nature 539, 384-389. doi: 10.1038/ nature 20134

Dever, D. P., and Porteus, M. H. (2017). The changing landscape of gene editing in hematopoietic stem cells: a step towards Cas9 clinical translation. Curr. Opin. Hematol. 24, 481-488. doi: 10.1097/MOH.0000000000000385

DeWitt, M. A., Magis, W., Bray, N. L., Wang, T., Berman, J. R., Urbinati, F., et al. (2016). Selection-free genome editing of the sickle mutation in human adult hematopoietic stem/progenitor cells. Sci. Transl. Med. 8:360ra134. doi: 10.1126/scitranslmed.aaf9336

Doudna, J. A. (2020). The promise and challenge of therapeutic genome editing. Nature 578, 229-236. doi: 10.1038/s41586-020-1978-5

Forget, B. G. (1998). Molecular basis of hereditary persistence of fetal hemoglobin. Ann. N. Y. Acad. Sci. 850, 38-44. doi: 10.1111/j.1749-6632.1998.tb10460.x

Fraser, P., and Grosveld, F. (1998). Locus control regions, chromatin activation and transcription. Curr. Opin. Cell Biol. 10, 361-365. doi: 10.1016/S0955-0674(98)80012-4

Fritsch, E. F., Lawn, R. M., and Maniatis, T. (1980). Molecular cloning and characterization of the human beta-like globin gene cluster. Cell 19, 959-972. doi: 10.1016/0092-8674(80)90087-2

Gaensler, K. M., Zhang, Z., Lin, C., Yang, S., Hardt, K., and Flebbe-Rehwaldt, L. (2003). Sequences in the (A)gamma-delta intergenic region are not required for stage-specific regulation of the human beta-globin gene locus. Proc. Natl. Acad. Sci. U.S.A. 100, 3374-3379. doi: 10.1073/pnas.0634132100

Galanello, R., Melis, M. A., Podda, A., Monne, M., Perseu, L., Loudianos, G., et al. (1990). Deletion delta-thalassemia: the $7.2 \mathrm{~kb}$ deletion of Corfu delta beta-thalassemia in a non-beta-thalassemia chromosome. Blood 75, 1747-1749. doi: 10.1182/blood.V75.8.1747.1747

Garner, C. P., Tatu, T., Best, S., Creary, L., and Thein, S. L. (2002). Evidence of genetic interaction between the beta-globin complex and chromosome $8 \mathrm{q}$ in the expression of fetal hemoglobin. Am. J. Hum. Genet. 70, 793-799. doi: $10.1086 / 339248$

Genovese, P., Schiroli, G., Escobar, G., Tomaso, T. D., Firrito, C., Calabria, A., et al. (2014). Targeted genome editing in human repopulating haematopoietic stem cells. Nature 510, 235-240. doi: 10.1038/nature13420

Grosveld, F., van Assendelft, G. B., Greaves, D. R., and Kollias, G. (1987). Positionindependent, high-level expression of the human beta-globin gene in transgenic mice. Cell 51, 975-985. doi: 10.1016/0092-8674(87)90584-8
Gundry, M. C., Brunetti, L., Lin, A., Mayle, A. E., Kitano, A., Wagner, D., et al. (2016). Highly efficient genome editing of murine and human hematopoietic progenitor cells by CRISPR/Cas9. Cell Rep. 17, 1453-1461. doi: 10.1016/j.celrep.2016.09.092

Haapaniemi, E., Botla, S., Persson, J., Schmierer, B., and Taipale, J. (2018). CRISPRCas9 genome editing induces a p53-mediated DNA damage response. Nat. Med. 24, 927-930. doi: 10.1038/s41591-018-0049-z

Hirakawa, M. P., Krishnakumar, R., Timlin, J. A., Carney, J. P., and Butler, K. S. (2020). Gene editing and CRISPR in the clinic: current and future perspectives. Biosci. Rep. 40, 1-37. doi: 10.1042/BSR20200127

Hoban, M. D., Cost, G. J., Mendel, M. C., Romero, Z., Kaufman, M. L., Joglekar, A. V., et al. Correction of the sickle cell disease mutation in human hematopoietic stem/progenitor cells. Blood (2015). 125, 2597-604. doi: 10.1182/blood-2014-12-615948

Ihry, R. J., Worringer, K. A., Salick, M. R., Frias, E., Ho, D., Theriault, K., et al. (2018). p53 inhibits CRISPR-Cas9 engineering in human pluripotent stem cells. Nat. Med. 24, 939-946. doi: 10.1038/s41591-018-0050-6

Ikawa, Y., Miccio, A., Magrin, E., Kwiatkowski, J. L., Rivella, S., and Cavazzana, M. (2019). Gene therapy of hemoglobinopathies: progress and future challenges. Hum. Mol. Genet. 28:R24-30. doi: 10.1093/hmg/ddz172

Komor, A. C., Badran, A. H., and Liu, D. R. (2017). CRISPR-based technologies for the manipulation of eukaryotic genomes. Cell 168, 20-36. doi: 10.1016/j.cell.2016.10.044

Komor, A. C., Badran, A. H., and Liu, D. R. (2018). Editing the genome without double-stranded DNA breaks. ACS Chem. Biol. 13, 383-388. doi: 10.1021/acschembio.7b00710

Koren, A., Levin, C., Dgany, O., Kransnov, T., Elhasid, R., Zalman, L., et al. (2008). Response to hydroxyurea therapy in beta-thalassemia. Am. J. Hematol. 83, 366-370. doi: 10.1002/ajh.21120

Kountouris, P., Lederer, C. W., Fanis, P., Feleki, X., Old, J., and Kleanthous, M. (2014). IthaGenes: an interactive database for haemoglobin variations and epidemiology. PLoS ONE 9:e103020. doi: 10.1371/journal.pone. 0103020

Kulozik, A. E., Yarwood, N., and Jones, R. W. (1988). The Corfu delta beta zero thalassemia: a small deletion acts at a distance to selectively abolish beta globin gene expression. Blood 71, 457-462. doi: 10.1182/blood.V71.2.457.457

Lattanzi, A., Meneghini, V., Pavani, G., Amor, F., Ramadier, S., Felix, T., et al. (2019). Optimization of CRISPR/Cas9 delivery to human hematopoietic stem and progenitor cells for therapeutic genomic rearrangements. Mol. Ther. 27, 137-150. doi: 10.1016/j.ymthe.2018.10.008

Lino, C. A., Harper, J. C., Carney, J. P., and Timlin, J. A. (2018). Delivering CRISPR: a review of the challenges and approaches. Drug Deliv. 25, 1234-1257. doi: 10.1080/10717544.2018.1474964

Liu, N., Hargreaves, V. V., Zhu, Q., Kurland, J. V., Hong, J., Kim, W., et al. (2018). Direct promoter repression by BCL11A controls the fetal to adult hemoglobin switch. Cell 173, 430-42 e17. doi: 10.1016/j.cell.2018. 03.016

Luc, S., Huang, J., McEldoon, J. L., Somuncular, E., Li, D., Rhodes, C., et al. (2016). Bcll1a Deficiency leads to hematopoietic stem cell defects with an aging-like phenotype. Cell Rep. 16, 3181-3194. doi: 10.1016/j.celrep. 2016.08.064

Maeda, T., Ito, K., Merghoub, T., Poliseno, L., Hobbs, R. M., Wang, G., et al. (2009). LRF is an essential downstream target of GATA1 in erythroid development and regulates BIM-dependent apoptosis. Dev. Cell. 17, 527-540. doi: 10.1016/j.devcel.2009.09.005

Magrin, E., Miccio, A., and Cavazzana, M. (2019). Lentiviral and genome-editing strategies for the treatment of beta-hemoglobinopathies. Blood 134, 1203-1213. doi: 10.1182/blood.2019000949

Martyn, G. E., Wienert, B., Kurita, R., Nakamura, Y., Quinlan, K. G. R., and Crossley, M. (2019). A natural regulatory mutation in the proximal promoter elevates fetal globin expression by creating a de novo GATA1 site. Blood 133, 852-856. doi: 10.1182/blood-2018-07-863951

Martyn, G. E., Wienert, B., Yang, L., Shah, M., Norton, L. J., Burdach, J., et al. (2018). Natural regulatory mutations elevate the fetal globin gene via disruption of BCL11A or ZBTB7A binding. Nat. Genet. 50, 498-503. doi: 10.1038/s41588-018-0085-0

Masuda, T., Wang, X., Maeda, M., Canver, M. C., Sher, F., Funnell, A. P., et al. (2016). Transcription factors LRF and BCL11A independently 
repress expression of fetal hemoglobin. Science 351, 285-289. doi: 10.1126/science.aad3312

Menzel, S., Garner, C., Gut, I., Matsuda, F., Yamaguchi, M., Heath, S., et al. (2007). A QTL influencing F cell production maps to a gene encoding a zincfinger protein on chromosome 2p15. Nat. Genet. 39, 1197-1199. doi: 10.1038/ ng2 108

Mettananda, S., Fisher, C. A., Hay, D., Badat, M., Quek, L., Clark, K., et al. (2017). Editing an alpha-globin enhancer in primary human hematopoietic stem cells as a treatment for beta-thalassemia. Nat. Commun. 8:424. doi: 10.1038/s41467-017-00479-7

Mettananda, S., Gibbons, R. J., and Higgs, D. R. (2015). alpha-Globin as a molecular target in the treatment of beta-thalassemia. Blood 125, 3694-3701. doi: 10.1182/blood-2015-03-633594

Muirhead, H., Cox, J. M., Mazzarella, L., and Perutz, M. F. (1967). Structure and function of haemoglobin. 3. A three-dimensional fourier synthesis of human deoxyhaemoglobin at 5.5 Angstrom resolution. J. Mol. Biol. 28, 117-56. doi: 10.1016/S0022-2836(67)80082-2

Nuez, B., Michalovich, D., Bygrave, A., Ploemacher, R., and Grosveld, F. (1995). Defective haematopoiesis in fetal liver resulting from inactivation of the EKLF gene. Nature 375, 316-318. doi: 10.1038/375316a0

Ottolenghi, S., Giglioni, B., Taramelli, R., Comi, P., and Gianni, A. M. (1982). Delta beta-Thalassemia and HPF. H. Birth Defects Orig. Artic. Ser. 18, 65-67.

Palstra, R. J., Tolhuis, B., Splinter, E., Nijmeijer, R., Grosveld, F., and de Laat, W. (2003). The beta-globin nuclear compartment in development and erythroid differentiation. Nat. Genet. 35, 190-194. doi: 10.1038/ng1244

Papasavva, P., Kleanthous, M., and Lederer, C. W. (2019). Rare opportunities: CRISPR/Cas-based therapy development for rare genetic diseases. Mol. Diagn. Ther. 23, 201-222. doi: 10.1007/s40291-019-00392-3

Park, S. H., Lee, C. M., Dever, D. P., Davis, T. H., Camarena, J., Srifa, W., et al. (2019). Highly efficient editing of the beta-globin gene in patient-derived hematopoietic stem and progenitor cells to treat sickle cell disease. Nucleic Acids Res. 47, 7955-7972. doi: 10.1093/nar/gkz475

Perkins, A. C., Sharpe, A. H., and Orkin, S. H. (1995). Lethal beta-thalassaemia in mice lacking the erythroid CACCC-transcription factor EKL. F. Nature 375, 318-322. doi: 10.1038/375318a0

Pevny, L., Simon, M. C., Robertson, E., Klein, W. H., Tsai, S. F., D’Agati, V., et al. (1991). Erythroid differentiation in chimaeric mice blocked by a targeted mutation in the gene for transcription factor GATA-1. Nature 349, 257-260. doi: $10.1038 / 349257 \mathrm{a} 0$

Platt, O. S. (2008). Hydroxyurea for the treatment of sickle cell anemia. N. Engl. J. Med. 358, 1362-1369. doi: 10.1056/NEJMct0708272

Porteus, M. (2016). Genome editing: a new approach to human therapeutics. Annu. Rev. Pharmacol. Toxicol. 56, 163-190. doi: 10.1146/annurev-pharmtox-010814-124454

Pourfarzad, F., von Lindern, M., Azarkeivan, A., Hou, J., Kia, S. K., Esteghamat, F., et al. (2013). Hydroxyurea responsiveness in beta-thalassemic patients is determined by the stress response adaptation of erythroid progenitors and their differentiation propensity. Haematologica 98, 696-704. doi: 10.3324/haematol.2012.074492

Psatha, N., Karponi, G., and Yannaki, E. (2016). Optimizing autologous cell grafts to improve stem cell gene therapy. Exp. Hematol. 44, 528-539. doi: 10.1016/j.exphem.2016.04.007

Psatha, N., Reik, A., Phelps, S., Zhou, Y., Dalas, D., Yannaki, E., et al. (2018). Disruption of the BCL11A erythroid enhancer reactivates fetal hemoglobin in erythroid cells of patients with beta-thalassemia major. Mol Ther Methods Clin Dev. 10, 313-326. doi: 10.1016/j.omtm.2018. 08.003

Rivella, S. (2012). The role of ineffective erythropoiesis in nontransfusion-dependent thalassemia. Blood Rev. 26(Suppl. 1):S12-S15. doi: 10.1016/S0268-960X(12)70005-X

Sankaran, V. G., Menne, T. F., Xu, J., Akie, T. E., Lettre, G., Van Handel, B., et al. (2008). Human fetal hemoglobin expression is regulated by the developmental stage-specific repressor BCL11A. Science 322, 1839-1842. doi: 10.1126/science.1165409

Sankaran, V. G., Xu, J., Byron, R., Greisman, H. A., Fisher, C., Weatherall, D. J., et al. (2011). A functional element necessary for fetal hemoglobin silencing. $N$. Engl. J. Med. 365, 807-814. doi: 10.1056/NEJMoa1103070
Schiroli, G., Conti, A., Ferrari, S., Della Volpe, L., Jacob, A., Albano, L., et al. (2019). Precise gene editing preserves hematopoietic stem cell function following transient p53-mediated DNA damage response. Cell Stem Cell 24, 551-65 e8. doi: 10.1016/j.stem.2019.02.019

Smithies, O., Gregg, R. G., Boggs, S. S., Koralewski, M. A., and Kucherlapati, R. S. (1985). Insertion of DNA sequences into the human chromosomal beta-globin locus by homologous recombination. Nature 317, 230-234. doi: $10.1038 / 317230 \mathrm{a} 0$

Stamatoyannopoulos, G. (1991). Human hemoglobin switching. Science 252:383 doi: $10.1126 /$ science.2017679

Steinberg, M. H., Chui, D. H., Dover, G. J., Sebastiani, P., and Alsultan, A. (2014). Fetal hemoglobin in sickle cell anemia: a glass half full? Blood 123, 481-485. doi: 10.1182/blood-2013-09-528067

Taher, A. T., Musallam, K. M., and Cappellini, M. D. (2009). Thalassaemia intermedia: an update. Mediterr. J. Hematol. Infect. Dis. 1:e2009004. doi: 10.4084/MJHID.2009.004

Thein, S. L. (2008). Genetic modifiers of the beta-haemoglobinopathies. Br. J. Haematol. 141, 357-366. doi: 10.1111/j.1365-2141.2008.07084.x

Thein, S. L. (2013). The molecular basis of beta-thalassemia. Cold Spring Harb. Perspect. Med. 3:a011700. doi: 10.1101/cshperspect.a011700

Tolhuis, B., Palstra, R. J., Splinter, E., Grosveld, F., and de Laat, W. (2002). Looping and interaction between hypersensitive sites in the active beta-globin locus. Mol. Cell 10, 1453-1465. doi: 10.1016/S1097-2765(02)00781-5

Traxler, E. A., Yao, Y., Wang, Y. D., Woodard, K. J., Kurita, R., Nakamura, Y., et al. (2016). A genome-editing strategy to treat beta-hemoglobinopathies that recapitulates a mutation associated with a benign genetic condition. Nat. Med. 22, 987-990. doi: 10.1038/nm.4170

Uda, M., Galanello, R., Sanna, S., Lettre, G., Sankaran, V. G., Chen, W., et al. (2008). Genome-wide association study shows BCL11A associated with persistent fetal hemoglobin and amelioration of the phenotype of beta-thalassemia. Proc. Natl. Acad. Sci. U.S.A. 105, 1620-1625. doi: 10.1073/pnas.0711566105

Vega, M. A. (1991). Prospects for homologous recombination in human gene therapy. Hum. Genet. 87, 245-253. doi: 10.1007/BF00200899

Viprakasit, V., Gibbons, R. J., Broughton, B. C., Tolmie, J. L., Brown, D., Lunt, P., et al. (2001). Mutations in the general transcription factor TFIIH result in beta-thalassaemia in individuals with trichothiodystrophy. Hum. Mol. Genet. 10, 2797-2802. doi: 10.1093/hmg/10.24.2797

Wainscoat, J. S., Thein, S. L., Wood, W. G., Weatherall, D. J., MetaxotouMavromati, A., Tzotos, S., et al. (1985). A novel deletion in the beta-globin gene complex. Ann. N. Y. Acad. Sci. 445, 20-27. doi: 10.1111/j.1749-6632.1985.tb17171.x

Walton, R. T., Christie, K. A., Whittaker, M. N., and Kleinstiver, B. P. (2020). Unconstrained genome targeting with near-PAMless engineered CRISPR-Cas9 variants. Science 368, 290-296. doi: 10.1126/science.aba8853

Wang, H., and Xu, X. (2017). Microhomology-mediated end joining: new players join the team. Cell Biosci. 7:6. doi: 10.1186/s13578-017-0136-8

Weatherall, D. J. (2008). Hemoglobinopathies worldwide: present and future. Curr. Mol. Med. 8, 592-599. doi: 10.2174/156652408786241375

Weber, L., Frati, G., Felix, T., Hardouin, G., Casini, A., Wollenschlaeger, C. et al. (2020). Editing a gamma-globin repressor binding site restores fetal hemoglobin synthesis and corrects the sickle cell disease phenotype. Sci Adv. 6:eaay9392. doi: 10.1126/sciadv.aay9392

Wienert, B., Funnell, A. P., Norton, L. J., Pearson, R. C., Wilkinson-White, L. E., Lester, K., et al. (2015). Editing the genome to introduce a beneficial naturally occurring mutation associated with increased fetal globin. Nat. Commun. 6:7085. doi: $10.1038 /$ ncomms 8085

Wienert, B., Martyn, G. E., Kurita, R., Nakamura, Y., Quinlan, K. G. R., and Crossley, M. (2017). KLF1 drives the expression of fetal hemoglobin in British HPF. H. Blood 130, 803-807. doi: 10.1182/blood-2017-02-767400

Wilber, A., Nienhuis, A. W., and Persons, D. A. (2011). Transcriptional regulation of fetal to adult hemoglobin switching: new therapeutic opportunities. Blood 117, 3945-3953. doi: 10.1182/blood-2010-11-316893

Wu, Y., Zeng, J., Roscoe, B. P., Liu, P., Yao, Q., Lazzarotto, C. R., et al. (2019). Highly efficient therapeutic gene editing of human hematopoietic stem cells. Nat. Med. 25, 776-783. doi: 10.1038/s41591-019-0401-y

Ye, L., Wang, J., Tan, Y., Beyer, A. I., Xie, F., Muench, M. O., et al. (2016). Genome editing using CRISPR-Cas9 to create the HPFH genotype in HSPCs: 
an approach for treating sickle cell disease and beta-thalassemia. Proc. Natl. Acad. Sci. U.S.A. 113, 10661-10665. doi: 10.1073/pnas.1612075113

Yu, C., Niakan, K. K., Matsushita, M., Stamatoyannopoulos, G., Orkin, S. H., and Raskind, W. H. (2002). X-linked thrombocytopenia with thalassemia from a mutation in the amino finger of GATA-1 affecting DNA binding rather than FOG-1 interaction. Blood 100, 2040-2045. doi: 10.1182/blood-2002-02-0387

Yu, K. R., Natanson, H., and Dunbar, C. E. (2016). Gene editing of human hematopoietic stem and progenitor cells: promise and potential hurdles. Hum. Gene Ther. 27, 729-740. doi: 10.1089/hum.2016.107

Yu, L., Myers, G., and Engel, J. D. (2020). Small molecule therapeutics to treat the beta-globinopathies. Curr. Opin. Hematol. 27, 129-140. doi: $10.1097 / \mathrm{MOH} .0000000000000579$

Zeng, J., Wu, Y., Ren, C., Bonanno, J., Shen, A. H., Shea, D., et al. (2020). Therapeutic base editing of human hematopoietic stem cells. Nat. Med. 26, 535-541. doi: 10.1038/s41591-020-0790-y
Zhou, D., Liu, K., Sun, C. W., Pawlik, K. M., and Townes, T. M. (2010). KLF1 regulates BCL11A expression and gamma- to beta-globin gene switching. Nat. Genet. 42, 742-744. doi: 10.1038/ng.637

Conflict of Interest: The authors declare that the research was conducted in the absence of any commercial or financial relationships that could be construed as a potential conflict of interest.

Copyright $\odot 2020$ Barbarani, Łabedz and Ronchi. This is an open-access article distributed under the terms of the Creative Commons Attribution License (CC BY). The use, distribution or reproduction in other forums is permitted, provided the original author(s) and the copyright owner(s) are credited and that the original publication in this journal is cited, in accordance with accepted academic practice. No use, distribution or reproduction is permitted which does not comply with these terms. 